\title{
Giant Somatosensory Evoked Potentials Coincident With Epileptiform Discharges in Acutely Comatose Patients
}

\author{
David A. Houlden, Mark I. Boulos, Brian J. Murray, Loretta Norton, \\ G. Bryan Young
}

\begin{abstract}
Background: The amplitude of the cortically generated somatosensory evoked potential (SSEP) is used to predict outcome in comatose patients. The relationship between epileptiform discharges and SSEP amplitude has not been elucidated in those patients. Methods: Bilateral median nerve SSEP and electroencephalograph (EEG) studies were performed in a comatose patient (patient 1) 1 day after cardiac surgery and repeated 4 days later. He had tranexamic acid administered before and during surgery. Another comatose patient (patient 2) had the same studies performed 1 day after sustaining 10 minutes of pulseless electrical cardiac activity. Results: Both comatose patients had epileptiform discharges (on EEG) that were coincident with giant cortically generated SSEPs. In patient 1, the EEG and SSEP studies repeated 5 days postoperatively showed no epileptiform discharges, and the cortically generated SSEP amplitude was decreased (normalized) compared with that obtained one day postoperatively. He emerged from coma and had a good recovery. Patient 2 died shortly after EEG and SSEP testing. Conclusions: Epileptiform discharges were associated with giant cortically generated median nerve SSEP amplitude (tranexamic acid was implicated in patient 1 and anoxic brain injury in patient 2). Accordingly, those who use the amplitude of cortically generated SSEPs for predicting outcome in comatose patients should consider the presence of epileptiform discharges (detected by EEG) as a potential confounding factor.
\end{abstract}

RÉSUMÉ: Des PES géants coïncidant avec des décharges épileptiformes chez des patients en coma aigu. Contexte: L'amplitude des potentiels évoqués somesthésiques (PES) générés par le cortex est utilisée pour prédire l'issue chez les patients comateux. La relation entre les décharges épileptiformes et l'amplitude des PES n'a pas été élucidée chez ces patients. Méthode: Nous avons effectué des études des PES des deux nerfs médians et de l'électroencéphalogramme chez un premier patient comateux le lendemain d'une chirurgie cardiaque et nous avons répété ces examens 4 jours plus tard. Il avait reçu de l'acide tranexamique avant et pendant la chirurgie. Un deuxième patient comateux a subi les mêmes examens le lendemain d'un épisode de 10 minutes d'activité électrique cardiaque sans pouls. Résultats: Les deux patients comateux présentaient des décharges épileptiformes à l'ÉEG, qui coïncidaient avec des PES géants générés par le cortex. Chez le premier patient, aucune décharge épileptiforme n'a été enregistrée à l'ÉEG et aux PES répétés 5 jours après la chirurgie et l'amplitude des PES générés par le cortex était diminuée (normalisée) par rapport à ce qui avait été enregistré le lendemain de la chirurgie. Il a repris conscience et il s'est rétabli. Le deuxième patient est décédé peu après que l'ÉEG et les PES aient été enregistrés. Conclusions: Les décharges épileptiformes étaient associées à une amplitude géante des PES du nerf médian générés au cortex (l'acide tranexaminique était en cause chez le premier patient et les séquelles de l'anoxie cérébrale chez le deuxième patient). Par conséquent, ceux qui utilisent l'amplitude des PES générés par le cortex pour prédire l'issue chez les patients comateux devraient prendre tenir compte du fait que la présence de décharges épileptiformes (détectées à l'ÉEG) peut être un facteur de confusion.

Keywords: Brain hypoxia, electroencephalography, neurophysiology, seizures, somatosensor, somatosensory evoked potentials doi:10.1017/cjn.2015.237

Can J Neurol Sci. 2015; 42: 317-323

Median nerve somatosensory evoked potential (SSEP) grading is useful for predicting functional outcome after traumatic and anoxic brain injury. ${ }^{1-3}$ Bilaterally preserved SSEPs obtained in the early stage after traumatic brain injury is associated with good outcome, whereas absent ones are associated with poor outcomes. With anoxic-ischemic insults, the absence of the N20 response with median nerve stimulation is almost always associated with an outcome no better than vegetative state, whereas N20 preservation is prognostically unreliable., ${ }^{4,5}$

Giant SSEPs have been found mainly in progressive myoclonic epilepsy ${ }^{6}$ and occasionally in nonconvulsive status epilepticus, ${ }^{7}$ in which there is increased cortical excitability. The finding of giant SSEPs in the context of acute encephalopathies is very unusual and has not been addressed for its pathogenesis and prognostic significance. In this article, we describe giant SSEPs that occurred in the context of frequent epileptiform discharges following acute brain insults. These cases illustrate the importance of interpreting the finding of giant SSEPs in association with etiology and pathophysiology.

From the Department of Medical Imaging, The Ottawa Hospital, Ottawa, Ontario, Canada (DH), Department of Medicine, Neurology, Sunnybrook Health Science Centre, Toronto, Ontario, Canada (MB, BM), Clinical Neurological Sciences, University of Western

Ontario, London, Ontario, Canada (LN, BY)

Received July 1, 2014. Final Revisions Submitted November 6, 2014. Correspondence to: David Houlden, The Ottawa Hospital, 1053 Carling Avenue, Ottawa, ON K1Y 4E9, Canada Email: dhoulden@toh.on.ca 


\section{METHODS \\ SSEPs}

SSEPs were obtained using a Cadwell Cascade (Cadwell Instruments, Kennewick, WA) at Sunnybrook Health Science Centre, Toronto, Ontario, for patient 1 and a VikingQuest (Viasys/Nicolet) at University Hospital, London, Ontario, for patient 2. For patient 1, the SSEP studies were obtained 1 day postoperatively (1 day after the onset of tonic-clonic seizures). The studies were repeated 5 days postoperatively. For patient 2, only one SSEP study was obtained ( 2 days after the onset of axial myoclonus). The median nerves were alternately stimulated by surface stimulators at each wrist with a stimulus intensity two times that necessary to evoke a visible thenar muscle twitch. The stimulus pulse duration was 0.1-0.2 milliseconds and the stimulus rate was $3.1-4.7 \mathrm{~Hz}$ depending on institution. SSEP recordings were obtained from surface electrodes (130 Meditrace Mini, Kendall) and from subdermal needle electrodes (Rochester Electromedical, Miami, FL) or electroencephalograph (EEG) disc electrodes (Natus Neurology Inc., Middleton, WI) on the scalp. Skin/ electrode impedance was kept below $5000 \mathrm{ohms}$. The locations of the recording electrode pairs were (1) ipsilateral Erb's point (EP)frontal pole electrode (Fpz); (2) the C2 spinous process (Cv2)-Fpz; and (3) the scalp overlying the contralateral somatosensory cortex (C3' or C4')-Fpz. For patient 1, two additional channels were used that were not used in patient 2; contralateral somatosensory cortex (C3' or C4')-ipsilateral somatosensory cortex (C3' or C4') and contralateral somatosensory cortex (C3' or C4')-contralateral EP. For patient, 2 one additional channel was used that was not used in patient 1; contralateral EP-ipsilateral EP (EP1-EP2). The SSEP was the averaged result of at least 500 stimulus presentations. The amplifier gain was $20 \mu \mathrm{V} /$ division and the recording bandpass was 3 $2000 \mathrm{~Hz}$. The sweep time was 75 milliseconds on the left and 80 milliseconds following right median nerve stimulation for patient 1 and 50 milliseconds bilaterally for patient 2 . The display scale was adjusted for optimum presentation of the SSEP waveforms (up to $1.2 \mu \mathrm{V} /$ division). Two SSEPs from each limb were superimposed for waveform reproducibility.

\section{EEG}

For patient 1, routine 20-channel EEGs were performed with sampling rates of $256 \mathrm{~Hz} /$ channel. A bipolar montage with standard disk electrodes was used, and impedances were kept under $5 \mathrm{KOhms}$. Recordings were 20-30 minutes in duration and were obtained on the same day as the SSEP studies for patient 1 (1 and 5 days postoperatively). Auditory and nail bed pressure stimuli were applied when patients were comatose.

For patient 2, continuous EEG was obtained 2 days after she became unresponsive (same day as SSEP for patient 2). A fourchannel bipolar EEG monitor (Datex-Ohmeda S/5 M-EEG Module; model \#898683-00 plugged into Datex-Ohmeda Critical care monitor, GE Healthcare, Helsinki, Finland), surface electrodes (3M Health Care2670-5), and a sub-hairline montage was used. The sampling rate was $100 \mathrm{~Hz}$.

\section{RESULTS}

\section{Patient 1}

Patient 1 was an 87-year-old male who underwent cardiac surgery at Sunnybrook Health Science Centre, Toronto, Ontario. His medical history included prior bypass surgery, critical aortic stenosis, angina, peripheral vascular disease, hyperlipidemia, hypertension, and atrial fibrillation. He underwent a repeat sternotomy, aortic valve replacement, and repair of the right coronary artery. The time on the bypass pump was 158 minutes and cross-clamp time was 108 minutes. He received 4 grams of tranexamic acid before surgery and a total of 14 grams during surgery as well as 2 grams of cefazolin before and 1 gram after surgery.

One day postoperatively, he developed recurrent generalized tonic-clonic seizures that lasted 5-60 seconds each. The patient was started on phenytoin and propofol was initiated given persistent convulsions. Over the next few days, propofol was successfully tapered with no recurrent seizures. Clonazepam was then introduced. Hypoxic injury was presumed.

\section{SSEP studies}

One day postoperatively, the peripheral nerve compound action potential recorded from EP-Fpz and the subcortically generated P/N13 waveform recorded from Cv2-Fpz were normal bilaterally. $\mathrm{EP}-\mathrm{P} / \mathrm{N} 13$ and P/N13 conduction times were normal bilaterally. Both recording montages (EP-frontal scalp [Fz], Cv2-Fz) showed unusual large amplitude late responses likely recorded from the $\mathrm{Fz}$ electrode. The cortically generated response recorded from somatosensory cortex (contralateral to side of stimulation)-Fpz had giant $\mathrm{N} 20-\mathrm{P} 25$ amplitude bilaterally; $34 \mu \mathrm{V}$ on the right and $15 \mu \mathrm{V}$ on the left side of the brain (upper limit of normal $=5.5 \mu \mathrm{V}]$ ) (Figure 1). ${ }^{8}$ Even N20 amplitude (measured from baseline to peak of N20) had giant amplitude bilaterally; $11 \mu \mathrm{V}$ on the right and $6.3 \mu \mathrm{V}$ on the left side of the brain (upper limit of normal $=2.7 \mu \mathrm{V}$ ). ${ }^{8}$ Five days postoperatively, the SSEP study was repeated and showed a large decrease of N20-P25 amplitude bilaterally compared with that obtained 1 day postoperatively; $4.8 \mu \mathrm{V}$ on the right and $6 \mu \mathrm{V}$ on the left side of the brain (compared with $34 \mu \mathrm{V}$ and $15 \mu \mathrm{V}$, respectively) (Figure 2). N20 amplitude was also decreased compared with the previous study; $3.3 \mu \mathrm{V}$ on the right and $4 \mu \mathrm{V}$ on the left side of the brain (compared with $11 \mu \mathrm{V}$ and $6.3 \mu \mathrm{V}$, respectively).

\section{EEG studies}

One day postoperatively, the EEG showed rare interictal spike and wave discharges generally less than one every 10 seconds and no more frequent than $1 \mathrm{~Hz}$ noted maximally around the right frontal/ temporal regions (Figure 3A). There were no changes in the EEG after auditory or nail bed pressure stimulation. After propofol was tapered, the discharges became more frequent and spread bilaterally with the left arm jerking clinically, eventually becoming confluent (Figure 3B). The patient had a generalized seizure following this recording; propofol was immediately resumed. Five days postoperatively, generalized slowing was noted on the EEG with prominent theta (in the context of multiple metabolic abnormalities which gradually resolved) and beta activity (reflecting medication effects). There were no stimulus-induced rhythmic, periodic, or ictal discharges.

\section{Imaging and outcome}

The patient emerged from coma 5 days postoperatively. A magnetic resonance imaging of the brain conducted 8 days postoperatively demonstrated atrophy and chronic ischemic changes but no acute infarct. He had a lengthy intensive care unit stay that was complicated by atrial fibrillation, pneumonia, and renal failure, and eventually the patient required tracheostomy. 

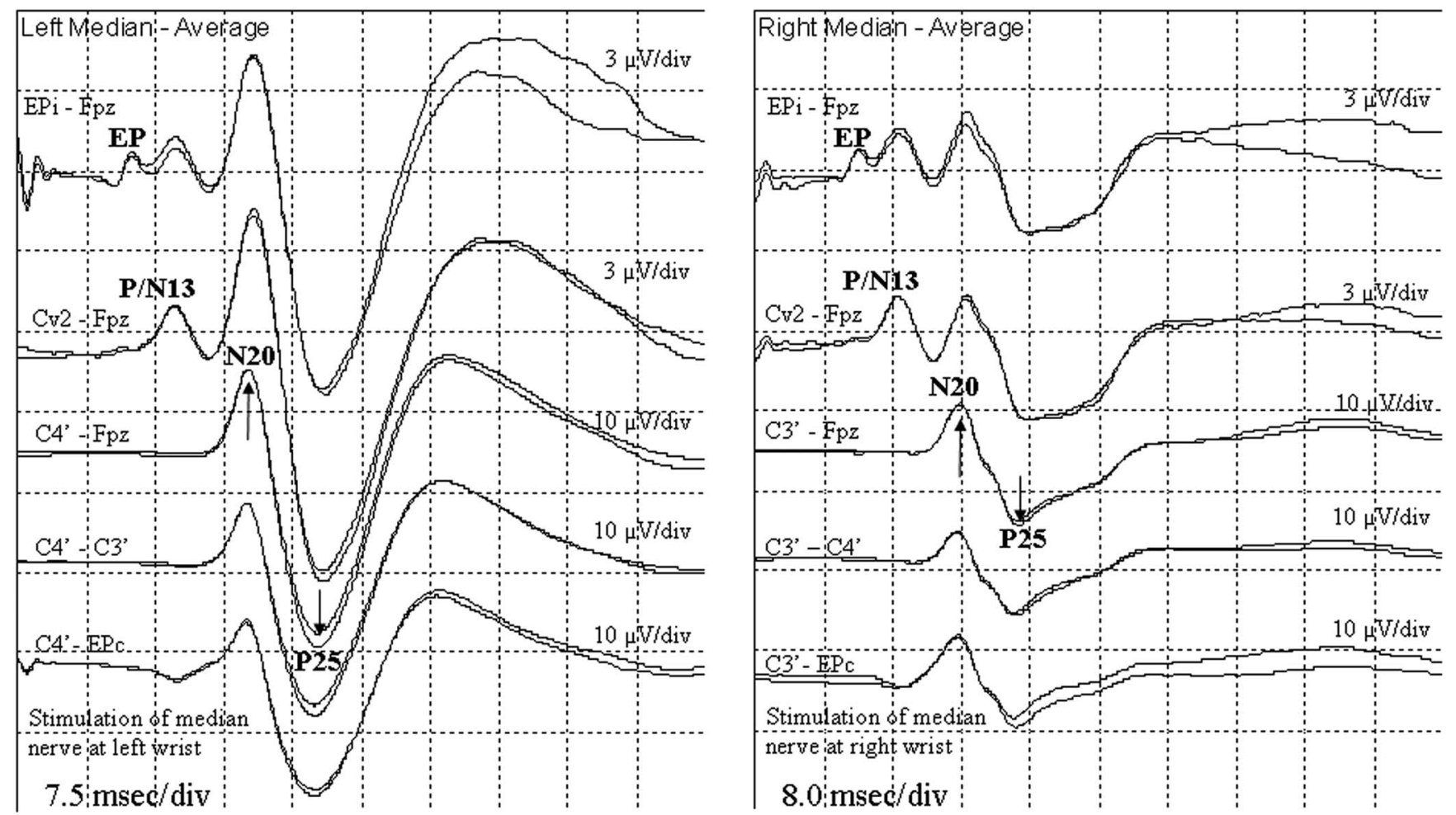

Figure 1: Left and right median nerve SSEPs (left and right side of figure, respectively) in patient 1 who was comatose 1 day after cardiac surgery. He received transexamic acid before and during surgery. Arrows indicate giant cortically generated SSEPs bilaterally. EP $i=E r b s$ point ipsilateral to stimulation; $E P c=E r b s$ point contralateral to stimulation; $C 4^{\prime}=$ right centroparietal scalp; C3' =left centroparietal scalp; msec/ div = milliseconds/division $; \mu$ V/div = microvolts per division; P/N13 = activity from base of medulla $; 20=$ activity from thalamus, thalamocortical radiation, and somatosensory cortex; $P 25=$ activity from somatosensory cortex.
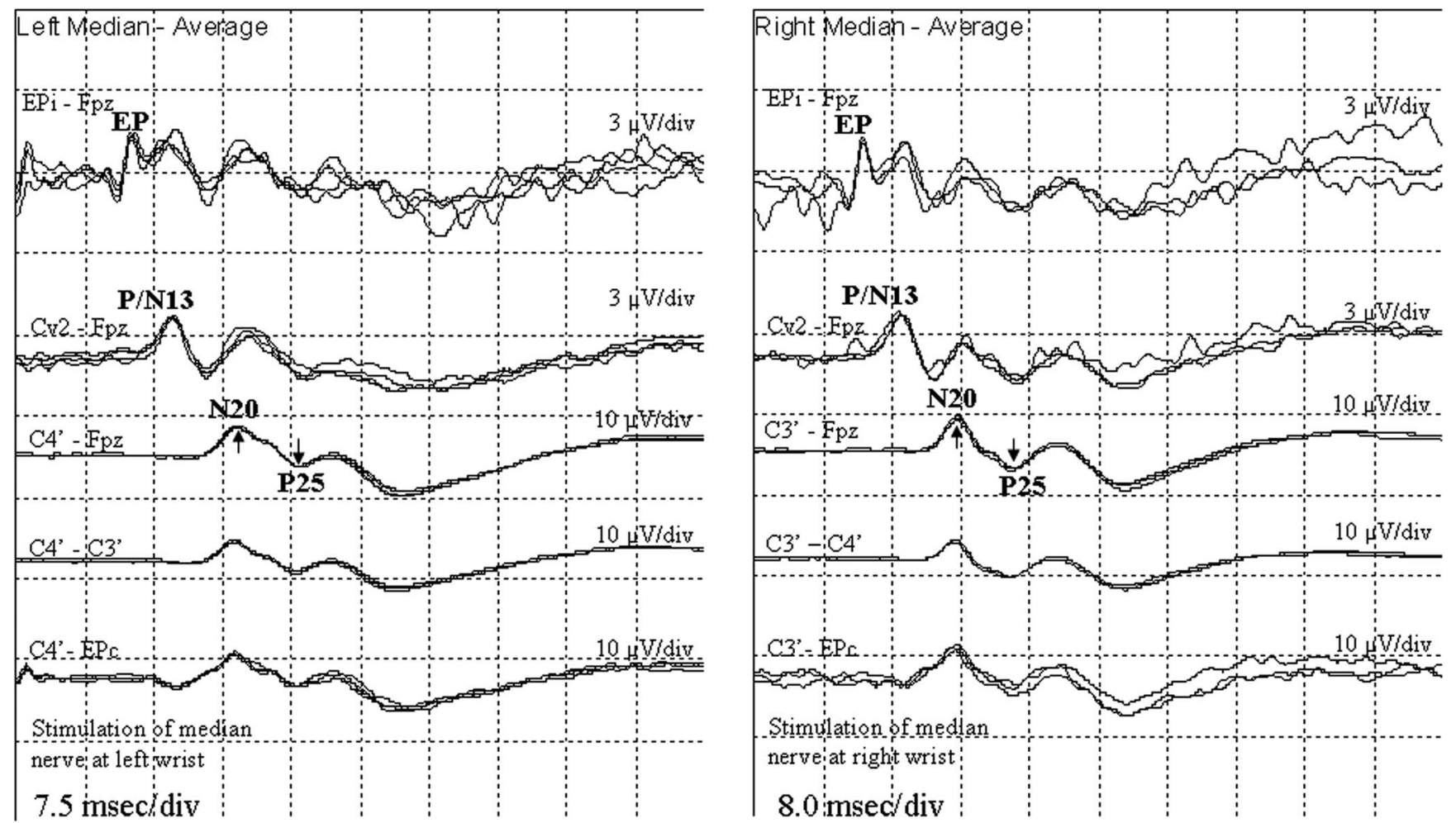

Figure 2: Left and right median nerve SSEPs (left and right side of figure, respectively) in patient 15 days after surgery. The cortically generated SSEP amplitude is normalized bilaterally (indicated by arrows), coincident with emergence from coma. See Figure 1 for abbreviations. 


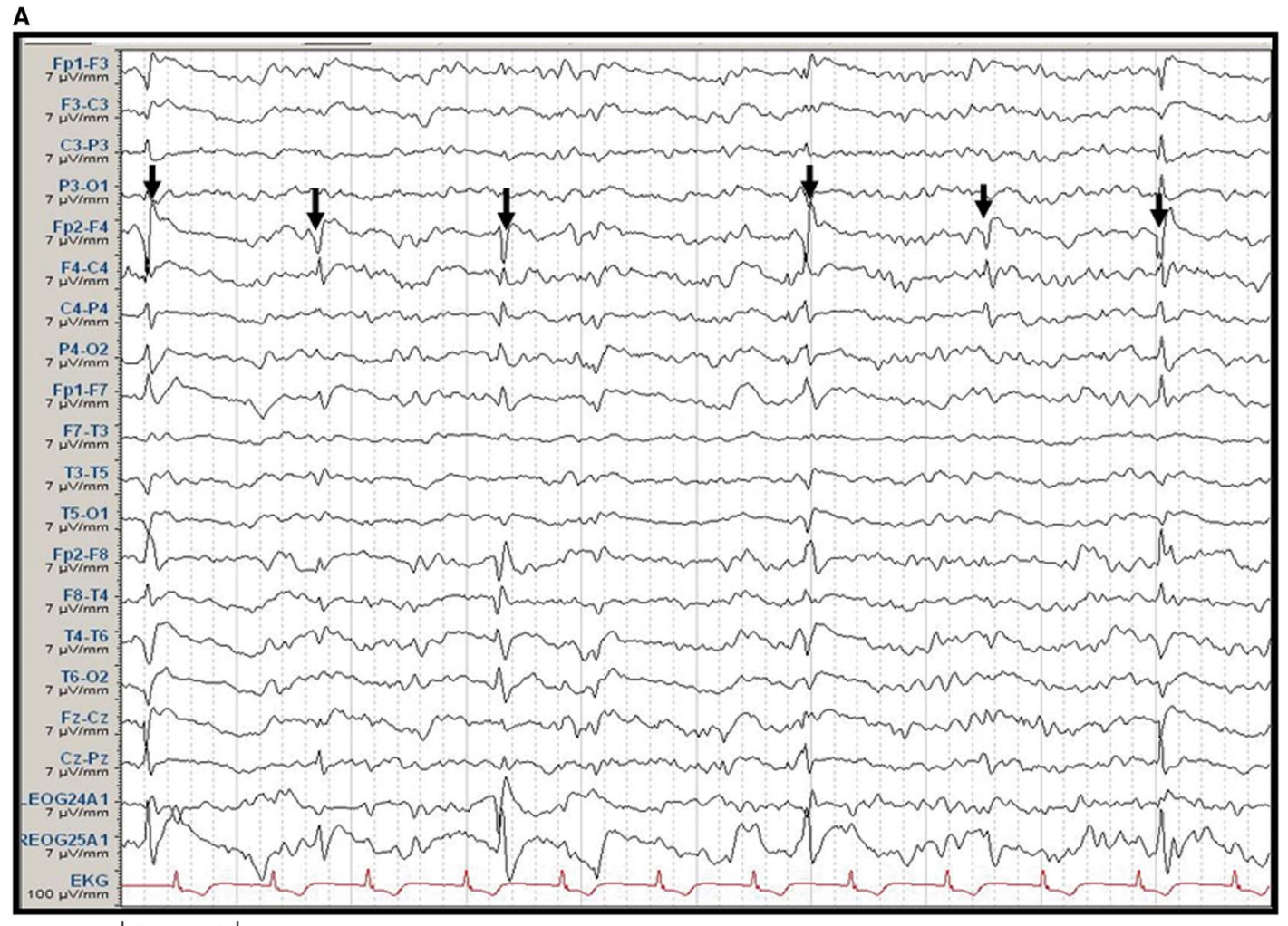

$\mid 5$ seconds $\mid$

B

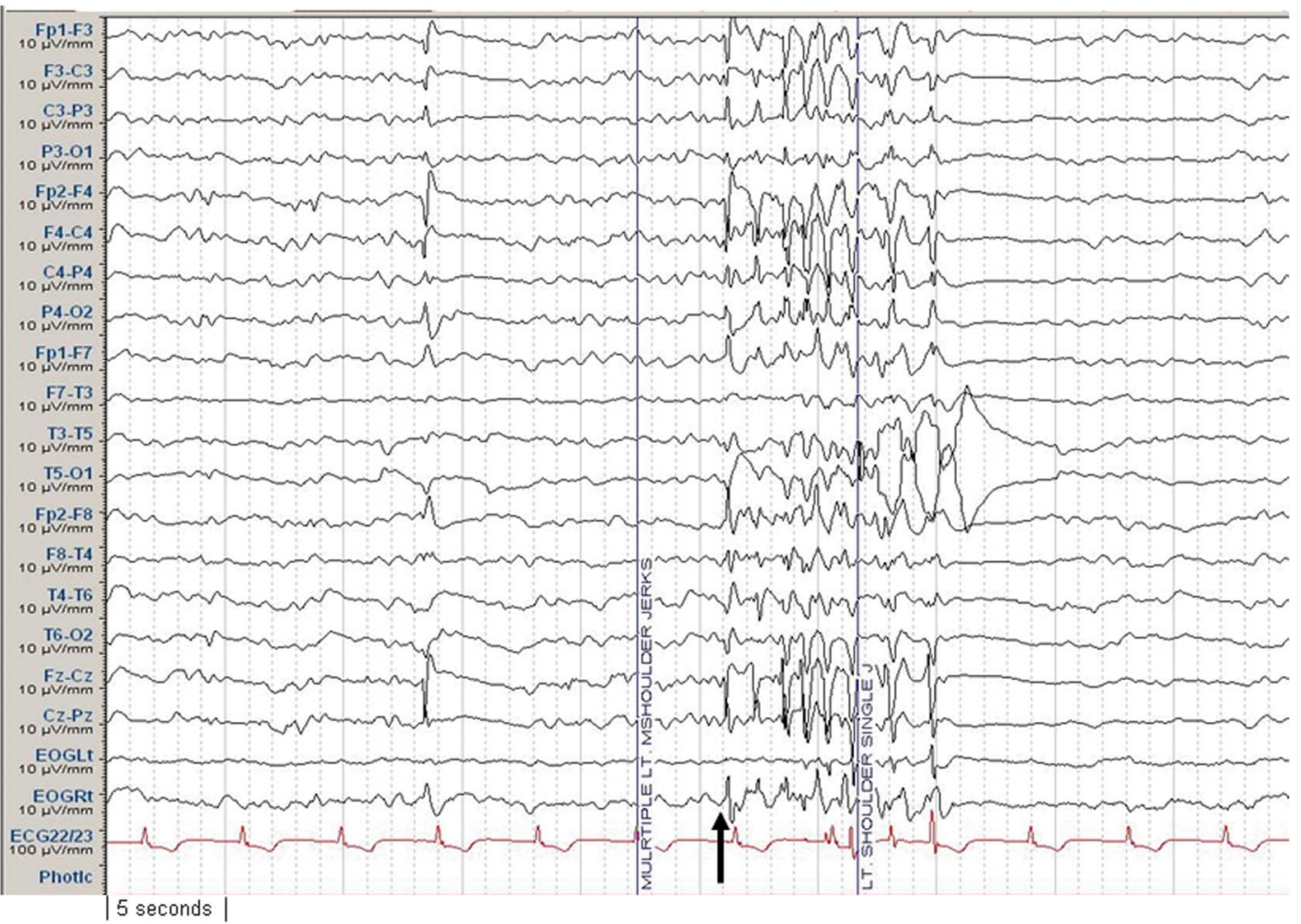

Figure 3: (A) Twenty-channel EEG (anteroposterior bipolar montage) recorded 1 day after cardiac surgery from patient 1, who was on propofol. He received transexamic acid before and during surgery. Arrows indicate rare interictal spike and wave discharges generally less than one every 10 seconds (no more frequent than $1 \mathrm{~Hz}$ ); maximal around the right frontal/temporal regions. (B) Propofol dose was tapered and epileptiform discharges became more frequent and spread bilaterally with the left arm jerking in this comatose patient. Arrow indicates onset of epileptiform discharges. 
However, he made a slow but continuous recovery over time. Upon discharge to rehabilitation, he was ambulating with assistance and his swallowing had improved dramatically. He provided signed informed consent to publish details of his case in accordance with our hospital research ethics board protocol.

\section{Patient 2}

Patient 2 was an 82-year-old female who underwent laparoscopic-assisted radical nephroureterectomy for an invasive transitional cell carcinoma at University Hospital, London, Ontario. Her postoperative course was uncomplicated; however, 3 days postoperatively she suffered pulseless electrical cardiac activity (PEA) and had hospital cardiopulmonary resuscitation measures for approximately 10 minutes before return of spontaneous circulation. She was transferred to the intensive care unit and was sedated, intubated, and required high vasopressor support. She subsequently developed significant axial myoclonus that day and was started on treatment of propofol and phenytoin and subsequently changed to valproic acid at the time when EEG and SSEP testing were performed.

\section{SSEP study}

The SSEP study (performed 2 days after PEA) showed a mildly delayed right EP response (probably related to a mild neuropathy from her chronic renal failure) but the morphology of the subcortically generated P/N13 waveform, the EP-P/N13 conduction time and the P/N13-N20 conduction time were normal bilaterally. As with patient 1 , both recording montages (EP-Fz, Cv2-Fz) showed unusually large amplitude late responses. The cortically generated response recorded from somatosensory cortex (contralateral to side of stimulation)-Fpz had giant N20-P25 amplitude bilaterally; $29 \mu \mathrm{V}$ on the right and $16.2 \mu \mathrm{V}$ on the left side of the brain (Figure 4). The N20 amplitude (measured from baseline to peak of N20) was high amplitude: $3.8 \mu \mathrm{V}$ on the right and $2.3 \mu \mathrm{V}$ on the left side of the brain. The P/N13-N20 interpeak latency was normal bilaterally.

\section{EEG study}

The EEG was also performed 2 days after PEA and revealed generalized periodic epileptiform discharges against a suppressed background (Figure 5). There were no stimulus-induced rhythmic, periodic, or ictal discharges.

\section{Imaging and outcome}

One day after PEA cardiac arrest, computed tomography of the head showed generalized brain atrophy and chronic ischemic changes (in keeping with the patient's age) but no acute intracranial abnormality. Two days after PEA, the neurological examination revealed absent corneal, gag, and pupillary reflexes. Given her clinical findings, the patient's prognosis was quite grim so substitute

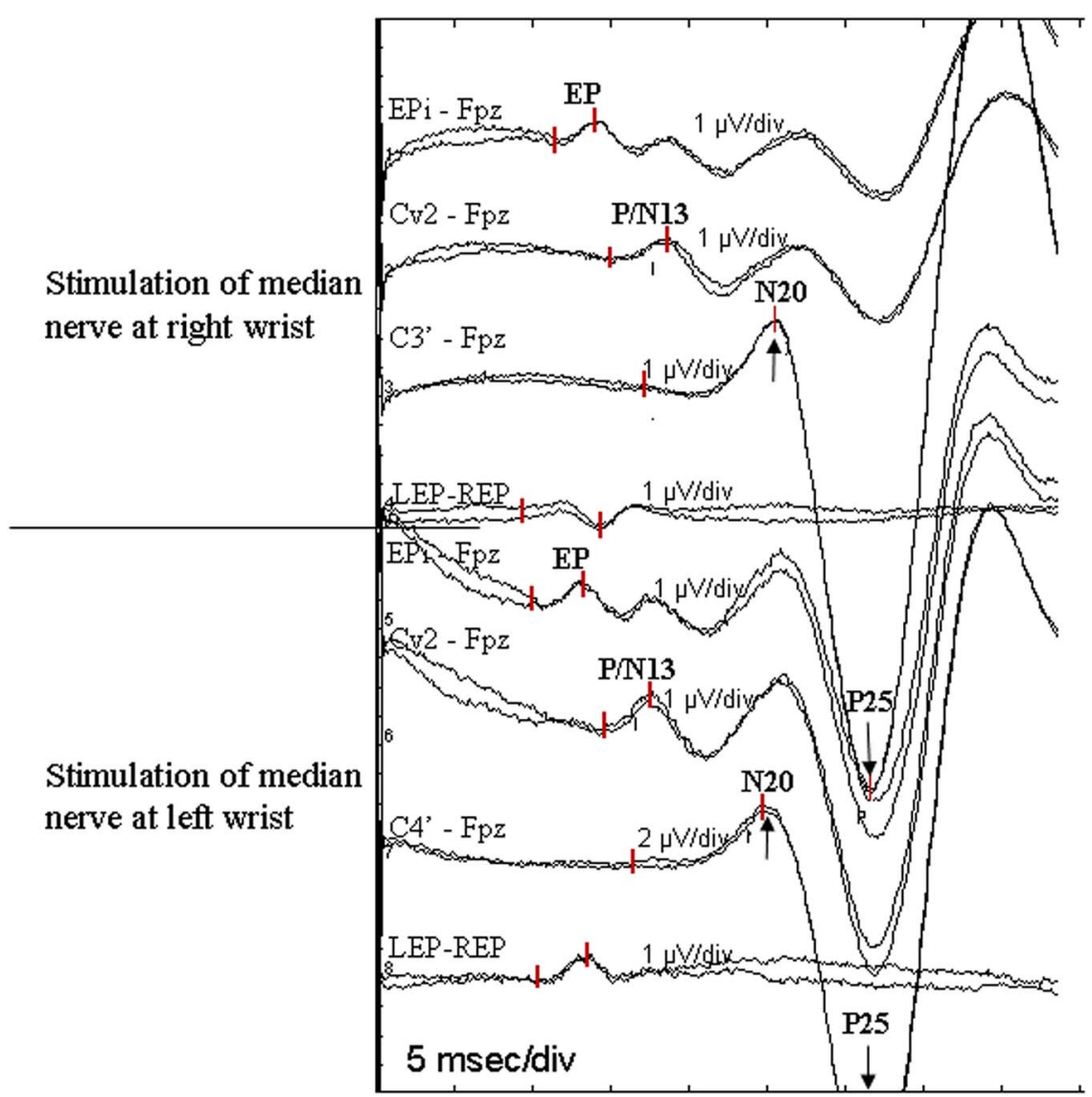

Figure 4: Right (top of figure) and left (bottom of figure) median nerve SSEPs in patient 2, who was comatose 2 days after pulseless electric cardiac activity. Arrows indicate giant cortically generated SSEPs bilaterally. See Figure 1 for abbreviations. 


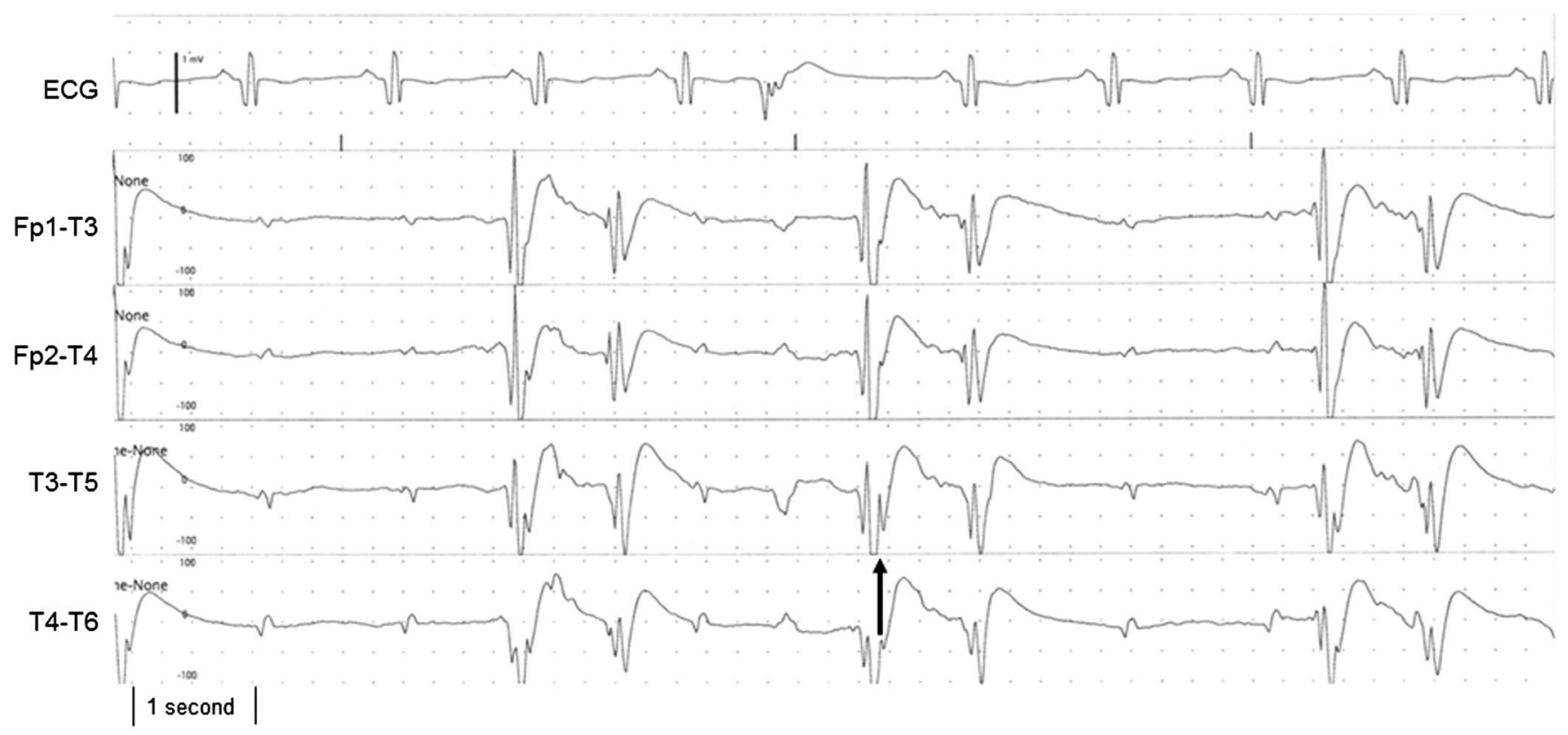

Figure 5: Four-channel EEG (bipolar sub-hairline montage) from patient 2 who was comatose 2 days after pulseless electric cardiac activity. EEG shows burst-suppression with generalized spikes within the bursts (arrow).

decision-makers decided to remove life-sustaining therapies and family wishes were honoured.

\section{DISCUSSION}

This is the first time that the relationship between giant SSEPs and EEG has been reported in patients whose coma was related to complications following surgery. The same phenomenon has been reported in a traumatic brain-injured patients. ${ }^{7}$ Giant median nerve SSEPs have been more commonly reported in patients with myoclonic epilepsy. ${ }^{\text {9-11 }}$

In addition to giant SSEP N20-P25 amplitudes, we found the amplitude of $\mathrm{N} 20$ itself (onset to negative peak) was also increased. N20 is thought to originate mainly from the thalamus with some contributions from thalamocortical radiation fibres and primary somatosensory cortex. We agree that cell bodies contribute to N20 amplitude because the temporary amplitude increase we observed in patient 1 can only occur by temporary facilitation or disinhibition of cell bodies (in thalamus and/or somatosensory cortex).

We propose the favourable outcome in patient 1 (despite initial seizures and transient giant SSEPs) was related to a reversible effect of drugs, notably tranexamic acid, used during cardiac surgery. We had previously noted this effect in two separate centers after the switch of aprotinin to high-dose tranexamic acid. ${ }^{12}$ Both tranexamic acid and cefazolin, used in this patient, can block gamma-amino butyric acid type A receptors, causing a reversible reduction in inhibition in the brain. ${ }^{13-15}$

The second patient suffered severe anoxic-ischemic cortical injury that proved fatal. The finding of giant SSEPs in this situation is unusual. We speculate that this resulted from an imbalance of neurotransmitter functions, with either decreased gamma-amino butyric acid or augmented excitatory transmitters, especially glutamic acid, or both, as has been described in neonatal hypoxic encephalopathy with seizures. ${ }^{9}$ However, unlike patient 1 , whose giant SSEPs were likely from a reversible drug effect, the neuronal damage was permanent and severe in patient 2 .

Median nerve SSEP N20-P25 amplitude in the early stage after coma is used for prediction of clinical outcome, ${ }^{1-3}$ so it is important to consider the relationship between epileptiform discharges and SSEP amplitude when interpreting the SSEP. Unfortunately, this relationship was not elucidated in previous SSEP prognostic studies (seizure history was not considered in previous studies). It is possible that the prognostic power of the SSEP was weakened in previous studies because some patients with present but abnormal SSEPs may have had underlying facilitation or disinhibition that erroneously increased cortically generated SSEP amplitude. For example, in a previous study, we showed that 4 of 30 patients with bilaterally normal SSEPs on day 1 had bad outcomes. ${ }^{3}$ Perhaps those four patients had concomitant epileptiform discharges and an erroneously increased SSEP N20-P25 amplitude on day 1. Given the findings in the current study, the prognostic information gained from intact SSEPs in comatose patients should be used with caution when epileptiform discharges are present.

In the current study, both patients 1 and 2 had giant SSEP N20-P25 amplitude and epileptiform discharges. The relationship between epileptiform discharges and SSEP amplitude was shown in patient 1 who had a marked reduction in epileptiform discharges between days 1 and 5 that was coincident with a decrease (normalization) in the cortically generated SSEP bilaterally. The patient emerged from coma in the same time frame.

\section{Conclusion}

Those who use cortically generated SSEP amplitude for predicting outcome in comatose patients should consider the presence of epileptiform discharges (detected by EEG) as a potential confounding factor. 


\section{DisClOSURES}

$\mathrm{DH}, \mathrm{BM}, \mathrm{LN}$, and BY do not have anything to disclose. MB is a researcher for and has received research support from the Canadian Stroke Network and ResMed Corporation and is a researcher for and received a grant from APF Innovation.

\section{REFERENCES}

1. Guerit JM. Medical technology assessment. EEG and evoked potentials in the intensive care unit. Neurophysiol Clin. 1999; 29:301-17.

2. Young GB, Doig G, Ragazzoni A. Anoxic-ischemic encephalopathy: clinical and electrophysiological associations with outcome. Neurocrit Care. 2005;2:159-64.

3. Houlden DA, Taylor AB, Feinstein A, et al. Early somatosensory evoked potential grades in comatose traumatic brain injured patients predict cognitive and functional outcome. Crit Care Med. 2010;38:167-74.

4. Wijdicks EF, Hijdra A, Young GB, Bassetti C, Weibe S. Practice parameter: prediction of outcome of comatose survivors after cardiopulmonary resuscitation: report of the Quality Standards Subcommittee of the American Academy of Neurology. Neurology. 2006;67:203-10.

5. Rossetti AO, Oddo M, Logroscino G, Kaplan PW. Prognostication after cardiac arrest and hypothermia: a prospective study. Ann Neurol. 2010;67:301-7.

6. Shibasaki H, Yamashita Y, Neshige R, Tobimatsu S, Fukui R. Pathogenesis of giant somatosensory evoked potentials in progressive myoclonic epilepsy. Brain. 1985;108:225-40.
7. Schorl M. Giant somatosensory evoked potentials as indicator of nonconvulsive status epilepticus. Letters to the editor. Clin Neurophysiol. 2008;119:724-8.

8. Chiappa KH. Short-latency somatosensory evoked potentials: Methodology. In: Chiappa KH, editor. Evoked Potentials in Clinical Medicine, 3rd ed. New York: Lippincott-Raven; 1997, P. 283-340.

9. Takeuchi H, Touge T, Miki H, Yamada A, Deguchi K, Nishioka M. Electrophysiological and pharmacological studies of somatosensory reflex myoclonus. Electromyogr Clin Neurophysiol. 1992;32:143-54.

10. Valeriani M, Restuccia D, Di Lazzaro V, Le Pera D, Tonali P. The pathophysiology of giant SEPs in cortical myoclonus: a scalp topography and dipolar source modeling study. EEG Clin Neurophysiol. 1997;104:122-31.

11. Shibasaki H, Hallett M. Electrophysiological studies of myoclonus. Muscle Nerve. 2005;31:157-74.

12. Murkin JM, Falter F, Granton J, Young B, Burt C, Chu M. High dose TXA is associated with nonischemic clinical seizures in cardiac surgical patients. Anesth Analg. 2010;110:350-53.

13. Bechtel TP, Slaughter RL, Moore TD. Seizures associated with high cerebrospinal fluid concentrations of cefalozin. Am J Hosp Pharm. 1980;37:271-73.

14. Furtmuller R, Schlag MG, Berger M, et al. Tranexamic acid, a widely used antifibrinolytic agent, causes convulsions by a gammaaminobutyric acid (A) receptor antagonistic effect. J Pharmacol Exp Ther. 2002;301:168-73.

15. Santos LH, Araujo AN, Fanchini A, Pena A, Delerue-Matos C, Montenegro MC. Ecotoxicological aspects related to the presence of pharmaceuticals in the aquatic environment. J Hazardous Mater. 2010;175:45-95. 